\title{
Short communication: Effect of supplementation with Lactobacillus casei Shirota on insulin sensitivity, $\beta$-cell function, and markers of endothelial function and inflammation in subjects with metabolic syndrome-A pilot study
}

\author{
N. J. Tripolt, ${ }^{* 1}$ B. Leber, $\dagger^{1}$ D. Blattl, $†$ M. Eder, ${ }^{*}$ W. Wonisch, $\ddagger$ H. Scharnagl,§ T. Stojakovic,§ \\ B. Obermayer-Pietsch, ${ }^{*}$ T. C. Wascher,\# T. R. Pieber, ${ }^{*}$ V. Stadlbauer, $\|^{2}$ and H. Sourij* \\ *Division of Endocrinology and Metabolism, \\ †Division of Transplantation Surgery, Department of Surgery, \\ †Institute of Physiological Chemistry, Center for Physiological Medicine, and \\ $\S$ Clinical Institute of Medical and Chemical Laboratory Diagnostics, Medical University of Graz, 8010 Graz, Austria \\ \#1st Medical Department, Hanusch Hospital, 1100 Vienna, Austria \\ IIMedical University of Graz, Division of Gastroenterology and Hepatology, 8010 Graz, Austria
}

\begin{abstract}
Based on animal studies, intake of probiotic bacteria was suggested to improve insulin sensitivity by reducing endotoxinemia and inflammation. The objective of this study was to determine the effects of supplementation with the probiotic strain Lactobacillus casei Shirota $(\mathrm{LcS})$ over 12 wk on insulin sensitivity, $\beta$-cell function, inflammation, and endothelial dysfunction parameters in subjects with metabolic syndrome. In a randomizedcontrolled study, 30 subjects with metabolic syndrome either received Lactobacillus casei Shirota 3 times daily for $12 \mathrm{wk}$ or served as controls with standard medical therapy. Fasting blood samples were taken and a 75 -g oral glucose tolerance test was performed to derive indices for insulin sensitivity and $\beta$-cell function. In addition, parameters to assess endothelial function and inflammation markers were determined. Even though the insulin sensitivity index significantly improved after 3 mo of probiotic supplementation $(0.058 \pm 0.021$ vs. $0.038 \pm 0.025)$, the change was not significantly different compared with the control group. No improvements were seen in additional indices of insulin sensitivity (quantitative insulin sensitivity check index, insulin sensitivity by oral glucose tolerance test, and homeostasis model assessment for insulin resistance) and $\beta$-cell function (first and second phase insulin secretion, and homeostasis model assessment for $\beta$-cell function). Probiotic supplementation resulted in a significant reduction in soluble vascular cell adhesion molecule-1 (sVCAM-1) level $(1,614 \pm 343$ vs. $1,418 \pm 265 \mathrm{ng} /$ $\mathrm{mL})$. No significant changes in parameters used to as-
\end{abstract}

Received June 22, 2012.

Accepted September 3, 2012.

${ }^{1}$ Both authors contributed equally to this work.

${ }^{2}$ Corresponding author: vanessa.stadlbauer@medunigraz.at sess low-grade inflammation or endothelial dysfunction were observed. Intake of LcS for $12 \mathrm{wk}$ in subjects with metabolic syndrome did not improve insulin sensitivity, $\beta$-cell function, endothelial function, or inflammation markers in this trial.

Key words: metabolic syndrome, Lactobacillus casei Shirota, insulin sensitivity, endothelial function

\section{Short Communication}

Obesity and insulin resistance are major risk factors for the development of the metabolic syndrome and type 2 diabetes mellitus, conditions contributing to accelerated atherosclerosis and increased mortality (Thomas et al., 2007; Whitlock et al., 2009). The pathogenesis of obesity is complex and thought to involve interplay between individual phenotype and environmental factors. More recently, altered gut microbiota has been suggested to be involved in the pathogenesis of obesity, because the ratio of Firmicutes to Bacteroides of the cecum microbiota in rodents was found to be significantly higher in obese mice than in lean counterparts (Ley et al., 2005). This finding of an altered distal gut microbiota was then confirmed and extended to humans (Ley et al., 2006). Additionally, these investigations in humans demonstrated that as obese people lose weight, the composition of microflora shifts and more closely resembles that of the lean individuals (Ley et al., 2006), suggesting that the microflora might be involved in the pathogenesis of obesity.

Furthermore, Larsen et al. (2010) showed that the intestinal microflora is substantially altered in diabetic compared with healthy individuals, and further studies showed an association of gut microflora with insulin resistance (Creely et al., 2007). Obesity and metabolic syndrome were shown to be associated with increased 
circulating markers of oxidative stress, low-grade inflammation, and endothelial dysfunction; in turn, these parameters are known to play a key role in atherosclerosis and subsequently cardiovascular complications (Keaney et al., 2003). Bacterial LPS derived from the intestinal microbiota was shown to trigger these inflammatory processes (Cani et al., 2007a), and therefore to cause insulin resistance and $\beta$-cell dysfunction (Cani et al., 2007a, 2008). However, despite several mechanistic studies and encouraging results in animals (Cani et al., 2008; Naito et al., 2011), interventional data on using probiotics in humans are sparse (Andreasen et al., 2010).

The aim of our study was to investigate the effect of supplementation with the probiotic strain Lactobacillus casei Shirota $(\mathbf{L c S})$ over $12 \mathrm{wk}$ on glucose tolerance and indices of insulin sensitivity and $\beta$-cell function as well as on markers of oxidative stress and inflammation in subjects with metabolic syndrome.

The present study was conducted according to the guidelines laid out in the Declaration of Helsinki (1996 revision), and all procedures involving human subjects were approved by the Ethics Committee of the Medical University of Graz. Written informed consent was obtained from all subjects.

Adult metabolic syndrome patients were identified from the outpatient clinic at the Division of Endocrinology and Metabolism at the Medical University of Graz (Austria). Metabolic syndrome was defined according to the modified NECP-ATP-III guidelines (Alberti et al., 2009). Patients treated with antibiotics within the previous $7 \mathrm{~d}$, on current antihyperglycemic treatment, any immunomodulatory therapy 1 mo before study entry, concomitant use of supplements (pre-, pro-, or synbiotics), inflammatory bowel disease (Crohn disease, ulcerative colitis) or celiac disease, or those with clinical signs of infectious diseases were excluded from participation.

This study was designed as a pilot study to obtain data to allow calculation of a sample size for a definitive trial. We performed a single-center, prospective, permuted-block, randomized controlled 12-wk clinical trial. Patients were randomized to receive either food supplementation with a milk drink containing LcS (three 65 -mL bottles a day, containing LcS at a concentration of $10^{8}$ cells $/ \mathrm{mL}$; Yakult Light, Yakult Austria, Vienna, Austria) for $12 \mathrm{wk}$ or to serve as a control subject (control group). Patients were randomized by using "randomizer" software (Institute for Medical Informatics, Statistics and Documentation, Medical University of Graz, Austria). All patients were advised to consume no other probiotic supplements during the study period and received a list of probiotic products available in Austria, which they had to avoid for the study period.
Participants were also advised not to change their diet or physical activity pattern while on the study. Subjects in the LcS group were provided with a pack of the milk drink every $2 \mathrm{wk}$; intervention adherence was assessed every $2 \mathrm{wk}$.

A frequently sampled 75-g oral glucose tolerance test (OGTT) was performed in all subjects after a 12-h overnight fast at baseline and at study end. Blood samples were collected before (0) and 15, 30, 60, 120, and $180 \mathrm{~min}$ after the glucose load to determine plasma glucose (Glc) and serum insulin (Ins) to calculate the indices described below.

The area under the curve for glucose during the OGTT was calculated using the trapezoidal rule. The insulin sensitivity index (ISI) was calculated from the OGTT according to 4 different equations:

(1) The Matsuda index (insulin sensitivity during

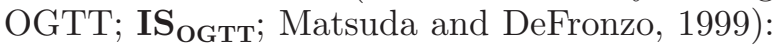

$$
\begin{gathered}
\mathrm{IS}_{\text {OGTT }}= \\
\frac{10,000}{\sqrt{\left(\mathrm{Glc}_{0} \times \mathrm{Ins}_{0}\right) \times(\text { mean Glc } \times \text { mean Ins })}},
\end{gathered}
$$

where $\mathrm{Glc}_{0}$ and $\mathrm{Ins}_{0}=$ glucose and insulin at baseline (i.e., fasting glucose and insulin).

(2) The homeostasis model assessment for insulin resistance (HOMA-IR; Matthews et al., 1985):

HOMA-IR $=\frac{\text { FPG }(\mathrm{mmol} / \mathrm{L}) \times \mathrm{FSI}(\mathrm{U} / \mathrm{L})}{22.5}$,

where $\mathrm{FPG}=$ fasting plasma Glc, and FSI $=$ fasting serum Ins.

(3) The quantitative insulin sensitivity check index (QUICKI; Katz et al., 2000):

$$
\text { QUICKI }=\frac{1}{\log \left(\operatorname{Ins}_{0}\right)+\log \left(\mathrm{Glc}_{0}\right)} .
$$

(4) The insulin sensitivity index as proposed by Stumvoll et al. (2001):

$$
\begin{aligned}
\text { ISI }= & 0.222-0.00333 \times \mathrm{BMI}-0.0000779 \\
& \times \mathrm{Ins}_{120}-0.000422 \times \text { age }
\end{aligned}
$$

where $\mathrm{BMI}=$ body mass index, and $\mathrm{Ins}_{120}=$ insulin at $120 \mathrm{~min}$.

$\beta$-Cell function was estimated in the fasting state by

$$
\text { HOMA- } \beta=\frac{20 \times \operatorname{Ins}_{0}}{\mathrm{Glc}_{0}-3.5}
$$


(Matthews et al., 1985) and during the OGTT by the Stumvoll index (Stumvoll et al., 2001):

First phase of insulin secretion $=1,283+1.829$

$$
\times \mathrm{Ins}_{30}-138.7 \times \mathrm{Glc}_{30}+3.772 \times \mathrm{Ins}_{0},
$$

Second phase of insulin secretion $=286+0.416$

$$
\times \mathrm{Ins}_{30}-25.94 \times \mathrm{Glc}_{30}+0.926 \times \mathrm{Ins}_{0},
$$

and the ratio of the incremental Ins to Glc response over the first 30 min during the OGTT $\left(\frac{\Delta \mathrm{Ins}_{30}}{\Delta \mathrm{Glc}_{30}}\right)$.

The HOMA indices were calculated using the mathematical estimation in a single fasting sample. For each test, Glc and Ins were expressed using the units of the original description. Glucose and insulin were measured by routine methods using commercially available kits.

Titers of antibodies against oxidized LDL (oLAb) were measured in serum with a commercial enzyme immunoassay (oLab, Biomedica, Vienna, Austria) according to the method of Tatzber and Esterbauer (1995). The assay is based on the binding reaction of the diluted samples $(1: 50)$ to the previously oxidized lowdensity lipoprotein (ox-LDL) by cupric ions bound to the microtiter wells. Detection was carried out by binding a secondary, peroxidase-coupled anti-IgG antibody, which permitted colorimetric detection of this enzyme with tetramethylbenzidine as substrate.

Cytokines IL-6, IL-10, soluble vascular cell adhesion molecule-1 (sVCAM-1), soluble intercellular cell adhesion molecule-1 (sICAM-1), and tumor necrosis factor- $\alpha(\mathbf{T N F}-\alpha)$ were determined by flow cytometry.

Table 1. Baseline characteristics of study subjects

\begin{tabular}{lcc}
\hline & \multicolumn{2}{c}{ Treatment $^{1}$} \\
\cline { 2 - 3 } Characteristic & LcS & Control \\
\hline Sex (female/male) & $4 / 9$ & $6 / 9$ \\
Age (yr) & $51 \pm 11$ & $55 \pm 9$ \\
Height (cm) & $175 \pm 8$ & $169 \pm 8^{\mathrm{a}}$ \\
Weight (kg) & $109 \pm 15$ & $91 \pm 14^{\mathrm{b}}$ \\
Blood pressure systolic (mmHg) & $147 \pm 19$ & $147 \pm 18$ \\
Blood pressure diastolic (mmHg) & $95 \pm 12$ & $94 \pm 18$ \\
Waist circumference (cm) & $113 \pm 12$ & $106 \pm 8$ \\
Total cholesterol (mmol/L) & $5.7 \pm 1.8$ & $5.5 \pm 1.4$ \\
High-density lipoproteins (mmol/L) & $1.1 \pm 0.4$ & $1.2 \pm 0.5$ \\
Low-density lipoproteins (mmol/L) & $3.3 \pm 1.3$ & $3.2 \pm 0.2$ \\
Triglycerides (mmol/L) & $2.5 \pm 1.9$ & $1.9 \pm 1.2$ \\
Very low density lipoproteins (mmol/L) & $1.2 \pm 0.9$ & $0.9 \pm 0.6$ \\
Hemoglobin A1c (\%) & $5.6 \pm 0.3$ & $6.0 \pm 0.6$ \\
\hline
\end{tabular}

${ }^{\mathrm{a}} P=0.05$ vs. probiotic group; ${ }^{\mathrm{b}} P<0.01$ vs. probiotic group.

${ }^{1}$ Thirty subjects with metabolic syndrome either received the probiotic Lactobacillus casei Shirota (LcS) 3 times daily for 12 wk or served as controls with standard medical therapy.
A FlowCytomix 5-plex assay (eBioscience, Vienna, Austria) of these cytokines was performed according to the manufacturer's instructions. Serum samples $(25$ $\mu \mathrm{L}$ ) were mixed with $25 \mu \mathrm{L}$ of bead mix and $50 \mu \mathrm{L}$ of biotin conjugate and, after a 2 -h incubation at room temperature, $50 \mu \mathrm{L}$ of streptavidin-phycoerythrin solution was added. After incubation for $1 \mathrm{~h}$ at room temperature, $200 \mu \mathrm{L}$ of assay buffer was added for measurement by LSRII Flow Cytometer (BD Biosciences Europe, Heidelberg, Germany). Cytokines were quantified using the FlowCytomix Pro 2.1 software (Bender MedSystems GmbH, Vienna, Austria).

Commercially available ELISA kits were used for determination of levels of von Willebrand factor ( $\mathbf{v W f}$; Eubio, Vienna, Austria), LPS-binding protein, soluble CD14 (Hycult Biotechnology, Uden, the Netherlands), and carbonyl proteins (Immundiagnostik, Bensheim, Germany).

Summarizing z-scores were calculated for inflammation and endothelial dysfunction, according to the Hoorn study publication (van Hecke et al., 2005).

All statistical analyses were performed using SPSS 18.0 software (SPSS Inc., Chicago, IL). Data are expressed as mean \pm standard deviation unless otherwise stated. The Mann-Whitney U-test or the unpaired Student's $t$-test was used for the comparison of differences between groups, and the paired Student's $t$-test or the Wilcoxon signed-rank test was used for the before and after treatment measurements, as appropriate for normally and non-normally distributed variables, respectively. Differences with a $P$-value $<0.05$ were considered statistically significant. A per protocol analysis was performed.

Thirty-five subjects were screened for the study between January and August 2010; 30 patients were included in the study and 28 completed the study (2 dropped out due to withdrawal of informed consent). Baseline characteristics of the insulin-resistant population are shown in Table 1. Subjects in the LcS group had a significantly greater height, weight, and BMI than those in the control group at baseline, whereas no significant difference in the other baseline characteristics, including diet and physical activity, could be observed between the 2 groups.

Three months of probiotic supplementation significantly improved ISI $(0.058 \pm 0.021$ vs. $0.038 \pm 0.025$ at baseline; $P<0.01$ ). However, the changes from baseline to 3 mo were not significantly different compared with those of the control group (Table 2). Further indices of insulin sensitivity, including measurements in the fasting state (HOMA-IR) or more dynamic estimates of insulin sensitivity during an OGTT (IS OGTT $_{\text {or }}$ QUICKI) did not show significant differences between the intervention groups (Table 2). 


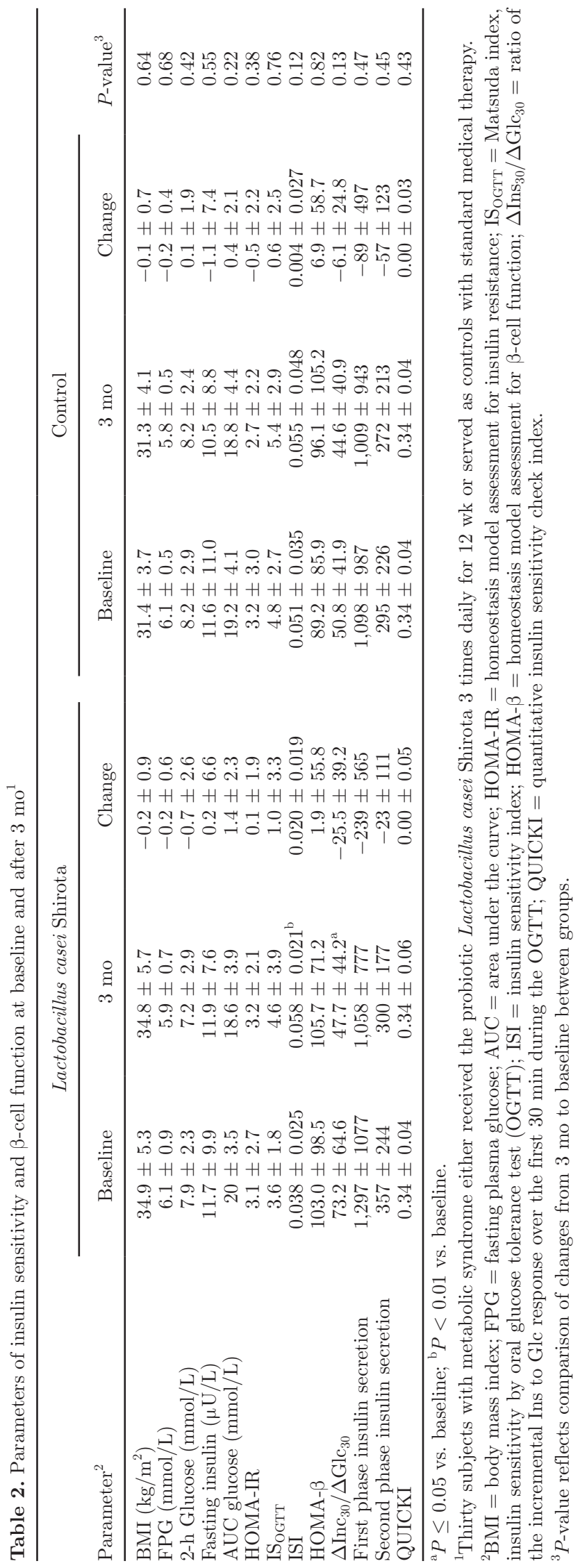

The ratio of incremental Ins to incremental Glc response over the first $30 \mathrm{~min}$ during the OGTT significantly decreased during treatment in the LcS group, but no significant difference in the change of this parameter between the 2 groups could be observed. Parameters of first and second phase insulin secretion or HOMA- $\beta$ did not change from baseline to study end (Table 2).

Probiotic supplementation resulted in a significant reduction in sVCAM-1 levels measured in serum $(1,614$ $\pm 343 \mathrm{ng} / \mathrm{mL}$ at baseline, $1,418 \pm 265 \mathrm{ng} / \mathrm{mL}$ at study end; $P=0.010)$. The reduction observed was significantly higher compared with that of the control group $(\Delta$ sVCAM-1: $-195 \pm 232$ in LcS vs. $30 \pm 182$ in control; $P=0.008)$.

Interestingly, 3 mo of probiotic supplementation significantly increased high sensitive c-reactive protein (hsCRP), from $3.66 \pm 4.03$ to $5.47 \pm 5.67 \mathrm{mg} / \mathrm{dL}(P$ $=0.037)$. No significant changes were observed in any other parameters assessing low-grade inflammation, such as ox-LDL, carbonyl protein, TNF- $\alpha$, vWf, IL-6, or endothelial dysfunction, including sum scores (Table $3)$.

In this study, we showed that LcS supplementation overall failed to improve parameters of insulin sensitivity, $\beta$-cell function, endothelial function, or low-grade inflammation. Although one single estimate of insulin sensitivity, the ISI, improved from baseline to study end in the LcS group, the changes from baseline to 3 mo were not significantly different between the LcS and control groups; therefore, this finding should not be over interpreted. By looking at different indices, we ensured that both aspects - hepatic and peripheral insulin sensitivity - were considered in our analysis.

The only parameter that improved significantly in the LcS group was sVCAM-1, but this finding could be a type I statistical error due to the small sample size, rather than a real sign of improvement in endothelial function or chronic inflammation, given that none of the other parameters assessed supported such a conclusion. Unexpectedly, we found a slight increase of hsCRP after supplementation with LcS for 3 mo. This finding has to be interpreted with great caution and could also be due to a type I statistical error. Although none of our patients reported any symptoms of infection or inflammation, this finding should be considered as a safety measure for future studies in patients with metabolic syndrome and probiotic treatment.

Among the numerous bacterial species described to alter gut flora and exert positive effects on the host, we chose to study LcS for several reasons. First, the commercially available milk drink preparation delivered a high bacterial number in a relatively small volume. Furthermore, LcS has been shown to survive passage through the stomach, is present in the lower intestinal 
Table 3. Parameters of inflammation and endothelial dysfunction at baseline and after 3 mo $^{1}$

\begin{tabular}{|c|c|c|c|c|c|c|c|}
\hline \multirow[b]{2}{*}{ Parameter $^{2}$} & \multicolumn{3}{|c|}{$\mathrm{LcS}$} & \multicolumn{3}{|c|}{ Control } & \multirow[b]{2}{*}{$P$-value ${ }^{3}$} \\
\hline & Baseline & $3 \mathrm{mo}$ & $\Delta$ & Baseline & $3 \mathrm{mo}$ & $\Delta$ & \\
\hline \multicolumn{8}{|l|}{ Inflammation } \\
\hline Inflammation z-score & $0.056 \pm 0.831$ & $0.107 \pm 0.797$ & $0.051 \pm 0.960$ & $-0.068 \pm 0.664$ & $0.170 \pm 0.600$ & $-0.103 \pm 0.753$ & 0.68 \\
\hline vWf (ng/mL) & $1,596.9 \pm 403.3$ & $1,477.7 \pm 445.2$ & $-119.2 \pm 379.9$ & $1,443.6 \pm 402.1$ & $1,288.9 \pm 392.3^{\mathrm{a}}$ & $-185.3 \pm 283.0$ & 0.60 \\
\hline IL-6 $(\mathrm{pg} / \mathrm{mL})$ & $\begin{array}{l}3.58 \\
(0.71 \text { to } 5.32)\end{array}$ & $\begin{array}{l}0.32 \\
(0.26 \text { to } 1.97)\end{array}$ & $\begin{array}{l}-2.98 \\
(-4.53 \text { to }-0.13)\end{array}$ & $\begin{array}{l}0.26 \\
(0.26 \text { to } 3.47)\end{array}$ & $\begin{array}{l}0.26 \\
(0.26 \text { to } 0.98)\end{array}$ & $\begin{array}{l}0.00 \\
(-3.47 \text { to } 0.98)\end{array}$ & 0.16 \\
\hline IL-10 (pg/mL) & $\begin{array}{l}7.05 \\
(0.26 \text { to } 12.08)\end{array}$ & $\begin{array}{l}0.26 \\
(0.26 \text { to } 0.26)\end{array}$ & $\begin{array}{l}-7.05 \\
(-12.08 \text { to } 0.00)\end{array}$ & $\begin{array}{l}0.26 \\
(0.26 \text { to } 11.51)\end{array}$ & $\begin{array}{l}0.26 \\
(0.26 \text { to } 9.89)\end{array}$ & $\begin{aligned} & 0.00 \\
&(-10.64 \text { to } 9.89)\end{aligned}$ & 0.27 \\
\hline TNF- $\alpha(\mathrm{pg} / \mathrm{mL})$ & $\begin{array}{l}15.1 \\
(1.3 \text { to } 27.8)\end{array}$ & $\begin{array}{l}0.3^{\mathrm{a}} \\
(0.3 \text { to } 15.4)\end{array}$ & $\begin{array}{c}-9.2 \\
(-22 \text { to } 0.0)\end{array}$ & $\begin{array}{l}15.1 \\
(0.0 \text { to } 24.0)\end{array}$ & (0.1 to 16.9$)$ & $\begin{array}{l}-5.2 \\
(-15.1 \text { to } 7.1)\end{array}$ & 0.62 \\
\hline Carbonyl protein (pmol/mg) & $\begin{array}{l}375.5 \\
(322.2 \text { to } 448.7)\end{array}$ & $\begin{array}{l}317.8^{\mathrm{b}} \\
(231.9 \text { to } 365.0)\end{array}$ & $\begin{array}{l}-77.6 \\
(-121.2 \text { to }-29.0)\end{array}$ & $\begin{array}{l}341.1 \\
(309.3 \text { to } 389.7)\end{array}$ & $\begin{array}{l}334.2 \\
(277.7 \text { to } 403.3)\end{array}$ & $\begin{array}{l}-11.6 \\
(-79.2 \text { to } 2.1)\end{array}$ & 0.14 \\
\hline Ox-LDL $(\mathrm{mU} / \mathrm{mL})$ & $563 \pm 483$ & $529 \pm 478$ & $-32 \pm 74$ & $556 \pm 432$ & $520 \pm 412$ & $-55 \pm 197$ & 0.76 \\
\hline $\begin{array}{l}\text { hsCRP }(\mathrm{mg} / \mathrm{L}) \\
\text { Endothelial fuction }\end{array}$ & $3.66 \pm 4.03$ & $5.47 \pm 5.67^{\mathrm{c}}$ & $1.86 \pm 2.48$ & $4.86 \pm 4.38$ & $3.10 \pm 3.45$ & $-1.60 \pm 5.24$ & 0.02 \\
\hline Endothelial z-score & $0.186 \pm 0.610$ & $0.137 \pm 0.597$ & $-0.049 \pm 0.339$ & $0.163 \pm 0.509$ & $0.120 \pm 0.470$ & $0.043 \pm 0.228$ & 0.40 \\
\hline sICAM-1 (ng/mL) & $884 \pm 572$ & $715 \pm 338$ & $-170 \pm 635$ & $692 \pm 271$ & $637 \pm 162$ & $-55 \pm 187$ & 0.51 \\
\hline sVCAM-1 (ng/mL) & $1,614 \pm 343$ & $1,418 \pm 265^{\mathrm{d}}$ & $-195 \pm 232$ & $1,468 \pm 3175$ & $1,498 \pm 273$ & $30 \pm 182$ & 0.008 \\
\hline
\end{tabular}

${ }^{\mathrm{a}-\mathrm{d}}$ Changes from baseline to $3 \mathrm{mo}:{ }^{\mathrm{a}} P=0.028 ;{ }^{\mathrm{b}} \mathrm{P}=0.028 ;{ }^{\mathrm{c}} \mathrm{P}=0.037 ;{ }^{\mathrm{d}} \mathrm{P}=0.010$.

Data are presented as means \pm standard deviation or, in the case of a skewed distribution, as medians (interquartile ranges).

$\delta \quad{ }^{2} \mathrm{vWf}=$ von Willebrand factor; $\mathrm{TNF}=$ tumor necrosis factor; $\mathrm{LDL}=$ low-density lipoprotein; Ox-LDL $=$ autoantibodies against oxidatively modified $\mathrm{LDL}$; hsCRP $=$ high sensitive c-reactive protein; sICAM-1 = soluble intercellular cell adhesion molecule-1; sVCAM-1 = soluble vascular cell adhesion molecule-1.

${ }^{3} P$-value reflects comparison of changes from baseline to 3 mo between groups. 
tract, and has been shown to reduce gram-negative bacteria, the source for LPS (Shirota et al., 1966). Matsumoto et al. (2010) showed that oral LcS affects the composition of intestinal microbiota and increases bifidobacteria.

Both obesity and insulin resistance are associated with low-grade inflammation, and several inflammatory factors such as TNF- $\alpha$ and IL-6 are related to impaired insulin action (Shirota et al., 1966). A high-fat diet was shown to induce low-grade endotoxinemia in mice, and infusing endotoxin causes weight gain and insulin resistance (Cani et al., 2007a) in mice.

Changes in gut microbiota composition are thought to decrease endotoxinemia and subsequently chronic inflammation and insulin resistance. In mice treated with antibiotics, changes in gut microbiota protected them against diet-induced fat mass development, glucose intolerance, and insulin resistance (Cani et al., 2008). A similar result was found in mice treated with a probiotic that increases the number of Bifidobacterium spp., which leads to improved glucose tolerance, insulin secretion, and a decrease in inflammatory tone (Cani et al., 2007b). Matsuzaki and coworkers (1997) showed that oral administration of LcS effectively decreased plasma glucose in $\mathrm{KK}-\mathrm{A}^{\mathrm{y}}$ mice, and finally, treatment of mice with a probiotic mixture (VSL\#3) decreased hepatic insulin resistance, supporting the concept that intestinal bacteria induce endogenous signals that play a pathogenic role in hepatic insulin resistance ( $\mathrm{Li}$ et al., 2003). Cani et al. (2007a) defined microbiota-derived LPS as the crucial factor in the development of inflammation in metabolic disease. Recently, animal studies have shown that LcS improves insulin resistances and lowers levels of proinflammatory cytokine (Naito et al., 2011; Zarfeshani et al., 2011). The lack of efficacy of $\mathrm{LcS}$ treatment in patients with metabolic syndrome in our study compared with animal studies could be due to several factors: (1) Unlike results in animal studies, LcS supplementation does not exert beneficial effects in humans with metabolic syndrome. Data from animal studies - especially those in rodents, who normally carry a different gut microbiome (Wos-Oxley et al., 2012) and where the pathophysiology of insulin resistance and inflammation is different (Cefalu, 2006) - are not necessarily transferable into the human setting. (2) Our study was a pilot trial and had insufficient power to answer this question definitively. However, we are not able to see at least a convincing trend in the markers investigated. (3) We do not know if the dose of probiotic was correct. In previous studies in individuals with alcoholic liver cirrhosis, this dose was shown to be effective on neutrophil function or cytokine response, but may be inadequate in subjects with metabolic syndrome (Gruber et al., 2008). We did not analyze stool samples and can therefore not prove that the gut microbiota really changed in our patients. (4) The duration of intervention could have been too short to influence the low-grade inflammatory process.

One limitation of the study was that BMI, by chance, was significantly higher in the LcS group because 4 patients with a BMI $>40 \mathrm{~kg} / \mathrm{m}^{2}$ were randomized to this group. However, the parameters observed did not differ significantly between these morbidly obese and the non-morbidly obese subjects and therefore we do not think that this factor had a major effect on the study results.

Another limitation of our study was the open label design and the lack of a milk-drink placebo for the control group. However, participants in the control group convincingly refrained from consuming probiotic drinks and we believe that the introduction of a probioticplacebo group would not have changed the results significantly with regard to the parameters investigated.

Our findings are in line with a recently published paper by Andreasen et al. (2010), which showed that in a mixed participant group including type 2 diabetics, subjects with impaired glucose tolerance, and healthy subjects, a 4 -wk treatment with Lactobacillus acidophilus NCFM did not affect systemic inflammation. Additionally, Andreasen et al. (2010) showed a beneficial effect of a 4 -wk treatment with Lactobacillus acidophilus NCFM on insulin sensitivity. However, they observed no significant improvement in insulin sensitivity in the probiotic treatment group from baseline to end of study, whereas insulin sensitivity in the placebo group significantly decreased. The significant difference observed between the groups in the study by Andreasen et al. (2010) might be due largely to the worsening in the placebo group rather than a real improvement caused by treatment.

In conclusion, intake of LcS for 12 wk in subjects with metabolic syndrome did not affect insulin sensitivity, $\beta$-cell function, endothelial function, or inflammation markers in this trial. Further studies using LcS in other dosages (e.g., adjusted for BW) or for a longer treatment period are needed to confirm our findings.

\section{ACKNOWLEDGMENTS}

Yakult Europe provided the milk drinks and supported the running costs of the study. Authors B. L., M. E., and N. J. T. are supported by the "Jubiläumsfond" of the Austrian National Bank (projects 12930 to V. S. and 13699 to H. S.) and the future fund of the federal state of Styria. Authors N. T., M. E., V. S., and H. S. carried out the study on the human volunteers. Laboratory analysis was performed by B. L., D. B., and B. O.P.; H. S. and T. C. W. provided statistical counseling; 
V. S. conceived the study; V. S. and H. S. designed the study; N. J. T., H. S., and V. S. drafted the manuscript; W. W. and T. R. P. helped in interpreting the data. All authors read and approved the final manuscript, and the authors report no conflicts of interest.

\section{REFERENCES}

Alberti, K. G., R. H. Eckel, S. M. Grundy, P. Z. Zimmet, J. I. Cleeman, K. A. Donato, J. C. Fruchart, W. P. James, C. M. Loria, and S. C. Smith Jr. 2009. Harmonizing the metabolic syndrome: A joint interim statement of the International Diabetes Federation Task Force on Epidemiology and Prevention; National Heart, Lung, and Blood Institute; American Heart Association; World Heart Federation; International Atherosclerosis Society; and International Association for the Study of Obesity. Circulation 120:1640-1645.

Andreasen, A. S., N. Larsen, T. Pedersen-Skovsgaard, R. M. Berg, K. Moller, K. D. Svendsen, M. Jakobsen, and B. K. Pedersen. 2010. Effects of Lactobacillus acidophilus NCFM on insulin sensitivity and the systemic inflammatory response in human subjects. Br. J. Nutr. 104:1831-1838.

Cani, P. D., J. Amar, M. A. Iglesias, M. Poggi, C. Knauf, D. Bastelica, A. M. Neyrinck, F. Fava, K. M. Tuohy, C. Chabo, A. Waget, E. Delmee, B. Cousin, T. Sulpice, B. Chamontin, J. Ferrieres, J. F. Tanti, G. R. Gibson, L. Casteilla, N. M. Delzenne, M. C. Alessi, and R. Burcelin. 2007a. Metabolic endotoxemia initiates obesity and insulin resistance. Diabetes 56:1761-1772.

Cani, P. D., R. Bibiloni, C. Knauf, A. Waget, A. M. Neyrinck, N. M. Delzenne, and R. Burcelin. 2008. Changes in gut microbiota control metabolic endotoxemia-induced inflammation in high-fat dietinduced obesity and diabetes in mice. Diabetes 57:1470-1481.

Cani, P. D., A. M. Neyrinck, F. Fava, C. Knauf, R. G. Burcelin, K. M. Tuohy, G. R. Gibson, and N. M. Delzenne. 2007b. Selective increases of bifidobacteria in gut microflora improve high-fat-dietinduced diabetes in mice through a mechanism associated with endotoxaemia. Diabetologia 50:2374-2383.

Cefalu, W. T. 2006. Animal models of type 2 diabetes: Clinical presentation and pathophysiological relevance to the human condition. ILAR J. 47:186-198.

Creely, S. J., P. G. McTernan, C. M. Kusminski, M. Fisher, N. F. Da Silva, M. Khanolkar, M. Evans, A. L. Harte, and S. Kumar. 2007. Lipopolysaccharide activates an innate immune system response in human adipose tissue in obesity and type 2 diabetes. Am. J. Physiol. Endocrinol. Metab. 292:E740-E747.

Gruber, S., K. Pinker, F. Riederer, M. Chmelik, A. Stadlbauer, M. Bittsansky, V. Mlynarik, R. Frey, W. Serles, O. Bodamer, and E. Moser. 2008. Metabolic changes in the normal ageing brain: Consistent findings from short and long echo time proton spectroscopy. Eur. J. Radiol. 68:320-327.

Katz, A., S. S. Nambi, K. Mather, A. D. Baron, D. A. Follmann, G. Sullivan, and M. J. Quon. 2000. Quantitative insulin sensitivity check index: A simple, accurate method for assessing insulin sensitivity in humans. J. Clin. Endocrinol. Metab. 85:2402-2410.

Keaney, J. F., Jr., M. G. Larson, R. S. Vasan, P. W. Wilson, I. Lipinska, D. Corey, J. M. Massaro, P. Sutherland, J. A. Vita, and E. J. Benjamin. 2003. Obesity and systemic oxidative stress: Clinical correlates of oxidative stress in the Framingham Study. Arterioscler. Thromb. Vasc. Biol. 23:434-439.

Larsen, N., F. K. Vogensen, F. W. van den Berg, D. S. Nielsen, A. S. Andreasen, B. K. Pedersen, W. A. Al-Soud, S. J. Sorensen, L. H. Hansen, and M. Jakobsen. 2010. Gut microbiota in human adults with type 2 diabetes differs from non-diabetic adults. PLoS One $5: \mathrm{e} 9085$.
Ley, R. E., F. Backhed, P. Turnbaugh, C. A. Lozupone, R. D. Knight, and J. I. Gordon. 2005. Obesity alters gut microbial ecology. Proc. Natl. Acad. Sci. USA 102:11070-11075.

Ley, R. E., P. J. Turnbaugh, S. Klein, and J. I. Gordon. 2006. Microbial ecology: Human gut microbes associated with obesity. Nature 444:1022-1023.

Li, Z., S. Yang, H. Lin, J. Huang, P. A. Watkins, A. B. Moser, C. Desimone, X. Y. Song, and A. M. Diehl. 2003. Probiotics and antibodies to TNF inhibit inflammatory activity and improve nonalcoholic fatty liver disease. Hepatology 37:343-350.

Matsuda, M., and R. A. DeFronzo. 1999. Insulin sensitivity indices obtained from oral glucose tolerance testing: Comparison with the euglycemic insulin clamp. Diabetes Care 22:1462-1470.

Matsumoto, K., T. Takada, K. Shimizu, K. Moriyama, K. Kawakami, K. Hirano, O. Kajimoto, and K. Nomoto. 2010. Effects of a probiotic fermented milk beverage containing Lactobacillus casei strain Shirota on defecation frequency, intestinal microbiota, and the intestinal environment of healthy individuals with soft stools. J. Biosci. Bioeng. 110:547-552.

Matsuzaki, T., R. Yamazaki, S. Hashimoto, and T. Yokokura. 1997. Antidiabetic effects of an oral administration of Lactobacillus casei in a non-insulin-dependent diabetes mellitus (NIDDM) model using KK-Ay mice. Endocr. J. 44:357-365.

Matthews, D. R., J. P. Hosker, A. S. Rudenski, B. A. Naylor, D. F. Treacher, and R. C. Turner. 1985. Homeostasis model assessment: Insulin resistance and beta-cell function from fasting plasma glucose and insulin concentrations in man. Diabetologia 28:412-419.

Naito, E., Y. Yoshida, K. Makino, Y. Kounoshi, S. Kunihiro, R. Takahashi, T. Matsuzaki, K. Miyazaki, and F. Ishikawa. 2011. Beneficial effect of oral administration of Lactobacillus casei strain Shirota on insulin resistance in diet-induced obesity mice. J. Appl. Microbiol. 110:650-657.

Shirota, M., K. Aso, and A. Iwabuchi. 1966. Studies on intestinal microflora. 1. Its constitution in healthy infants and the effect of oral administration of L. acidophilus strain Shirota. Nippon Saikingaku Zasshi 21:274-283.

Stumvoll, M., T. Van Haeften, A. Fritsche, and J. Gerich. 2001. Oral glucose tolerance test indexes for insulin sensitivity and secretion based on various availabilities of sampling times. Diabetes Care 24:796-797.

Tatzber, F., and H. Esterbauer. 1995. Autoantibodies to oxidized low-density lipoprotein. Pages $245-262$ in Free Radicals IX. G. Bellomo, G. Finardi, E. Maggi, and C. Rice-Evans, ed. Richelieu Press, London, UK.

Thomas, G. N., C. M. Schooling, S. M. McGhee, S. Y. Ho, B. M. Cheung, N. M. Wat, E. D. Janus, K. S. Lam, and T. H. Lam. 2007. Metabolic syndrome increases all-cause and vascular mortality: The Hong Kong Cardiovascular Risk Factor Study. Clin. Endocrinol. (Oxf.) 66:666-671.

van Hecke, M. V., J. M. Dekker, G. Nijpels, A. C. Moll, R. J. Heine, L. M. Bouter, B. C. P. Polak, and C. D. A. Stehouwer. 2005. Inflammation and endothelial dysfunction are associated with retinopathy: The Hoorn Study. Diabetologia 48:1300-1306.

Whitlock, G., S. Lewington, P. Sherliker, R. Clarke, J. Emberson, J. Halsey, N. Qizilbash, R. Collins, and R. Peto. 2009. Body-mass index and cause-specific mortality in 900000 adults: Collaborative analyses of 57 prospective studies. Lancet 373:1083-1096.

Wos-Oxley, M., A. Bleich, A. P. Oxley, S. Kahl, L. Janus, A. Smoczek, H. Nahrstedt, M. Pils, S. Taudien, M. Platzer, H. J. Hedrich, E. Medina, and D. Pieper. 2012. Comparative evaluation of establishing a human gut microbial community within rodent models. Gut Microbes 3:234-249.

Zarfeshani, A., H. Khaza'ai, R. Mohd Ali, Z. Hambali, K. Wahle, and M. Mutalib. 2011. Effect of Lactobacillus casei Shirota on the production of pro-inflammatory markers in streptozotocin-induced diabetic rats. Probiotics Antimicrob. Proteins 3:168-174. 